\title{
Selected Publications by Jayme Luiz Szwarcfiter
}

1. Donald E. Knuth and Jayme L. Szwarcfiter, A Structured Program to Generate All Topological Sorting Arrangements, Information Processing Letters 6 (1974), 153-157.

2. Jayme L. Szwarcfiter and Peter E. Lauer, A Search Strategy for the Elementary Cycles of a Directed Graph, Bit 16 (1976), 192-204.

3. Jayme L. Szwarcfiter and Leslie B. Wilson, Some Properties of Ternary Trees, The Computer Journal 21 (1978), 66-72.

4. Jayme L. Szwarcfiter, Systems of Distinct Representative for $k$ Families of Sets, Information Processing Letters 9 (1979), 195-196.

5. Alon Itai, Christos H. Papadimitriou, and Jayme L. Szwarcfiter, Hamilton Paths in Grid Graphs, SIAM Journal on Computing 11 (1982), 676-686.

6. Jayme L. Szwarcfiter, Optimal Multiway Search Trees for Variable Size Keys, Acta Informatica 21 (1984), 47-60.

7. Jayme L. Szwarcfiter, Grafos e Algoritmos Computacionais, Editora Campus, Rio de Janeiro, 1984, 216 pages.

8. Jayme L. Szwarcfiter, Ronaldo C. M. Persiano, and Antônio A. F. Oliveira, Orientations with Single Source and Sink, Discrete Applied Mathematics 10 (1985), 313-321.

9. Jayme L. Szwarcfiter, On Digraphs with a Rooted Tree Structure, Networks 15 (1985), 46-57.

10. Jayme L. Szwarcfiter, A Note on the Computation of the $k$-Closure of a Graph, Information Processing Letters 24 (1987), 279-280.

11. Jayme L. Szwarcfiter, Job Shop Scheduling with Unit Time Operations Under Resource Constraints and Release Dates, Discrete Applied Mathematics 18 (1987), 227-233.

12. Jacek Błażewicz, W. Kubiak, Hans Rock, and Jayme L. Szwarcfiter, Minimizing Mean Flow Time with Parallel Processors and Resource Constraints, Acta Informatica 24 (1987), 513-524.

13. Jacek Błażewicz, W. Kubiak, and Jayme L. Szwarcfiter, Scheduling Unit Time Tasks on Flow Shops Under Resource Constraints, Annals of Operations Research 16 (1988), 255-266.

14. Jayme L. Szwarcfiter On Minimum Cuts of Cycles and Maximum Disjoint Cycles, in Proceedings of the AMS-SIAM-IMS Joint Research Conference on Graphs and Algorithms, University of Colorado, Boulder, USA, 1987, R.B. Richter, ed., Graphs and Algorithms; Contemporary Mathematics 89 (1989), pp. $153-166$. 
15. Jayme L. Szwarcfiter and Magali A. Barroso, Enumerating the Maximal Cliques of a Circle Graph, in Proceedings of the 2nd International Conference on Graph Theory, Combinatorics, Algorithms and Applications, San Francisco State University, San Francisco, USA, 1989, Y. Alavi, F.R.K. Chung, R.L. Graham, and D.F. Hsu, eds., Graph Theory, Combinatorics, Algorithms and Applications, pp. 511-517, SIAM Publications, Philadelphia, USA, 1991.

16. Jacek Błażewicz, W. Kubiak, and Jayme L. Szwarcfiter, "Scheduling Fixed Type Tasks", in R. Slowinski and J. Werglasz, eds., Advances in Project Scheduling, pp. 225-236, Elsevier Science Publ., Amsterdam, 1989.

17. Mónica Villanueva I. and Jayme L. Szwarcfiter, Triangulated Graphs: a survey, Investigación Operativa 2 (1992), 245-271.

18. Jayme L. Szwarcfiter, Célia P. de Mello, and Celina M. H. de Figueiredo, On Transitive Orientations with Prescribed Sources and Sinks, Congressus Numeratium 98 (1993), 191-198.

19. Edson Cáceres, Narsingh Deo, N. Satry, and Jayme L. Szwarcfiter, On Finding Euler Tours in Parallel, Parallel Processing Letters 3 (1993), 223-231.

20. Jayme L. Szwarcfiter and Guy Chaty, Enumerating the Kernels of a Directed Graph with no Odd Circuits, Information Processing Letters 51 (1994), 149153.

21. Jayme L. Szwarcfiter and Claudson F. Bornstein, Clique Graphs of Chordal and Path Graphs, SIAM Journal on Discrete Mathematics 7 (1994), 331-336.

22. Jayme L. Szwarcfiter e Lilian Markenzon, Estruturas de Dados e seus Algoritmos, Livros Técnicos e Científicos, Rio de Janeiro, 1994, 320 pages.

23. Jayme L. Szwarcfiter, On Edge Transitivity of Directed Graphs, Discrete Mathematics 141 (1995), 227-235.

24. Claudson F. Bornstein and Jayme L. Szwarcfiter, On Clique Convergent Graphs, Graphs and Combinatorics 11 (1995), pp.213-220.

25. Jayme L. Szwarcfiter, Recognizing Clique Helly Graphs, Ars Combinatoria 45 (1997), pp.29-32.

26. Celina M. H. de Figueiredo, John Gimbel, Célia P. de Mello, and Jayme L. Szwarcfiter, Sources and Sinks in Comparability Graphs, Order 14 (1997), $75-83$.

27. M. Moscarini, R. Petreschi, and Jayme L. Szwarcfiter, On Node Searching and Starlike Graphs, Congressus Numerantium 131 (1998), 75-84.

28. Carmen Ortiz Z, Nelson Maculan, and Jayme L. Szwarcfiter, Characterizing and Edge Colouring Split-Indifference Graphs, Discrete Applied Mathematics 83 (1998), 177-185.

29. Claudio L. Lucchesi, Célia P. de Mello, and Jayme L. Szwarcfiter. On Clique Complete Graphs, Discrete Mathematics 183 (1998), 247-254. 
30. Claudson F. Bornstein and Jayme L. Szwarcfiter, Iterated Clique Graphs with Increasing Diameters, Journal of Graph Theory 28 (1998), 147-154.

31. Celina M. H. de Figueiredo, John Gimbel, Célia P. de Mello and Jayme L. Szwarcfiter, Even and Odd Pairs in Comparability and $P_{4}$-Comparability Graphs, Discrete Applied Mathematics 91 (1999), 293-297.

32. Erich Prisner and Jayme L. Szwarcfiter, Recognizing Clique Graphs of Directed and Rooted Path Graphs, Discrete Applied Mathematics 94 (1999), $321-328$.

33. Valmir C. Barbosa and Jayme L. Szwarcfiter, Generating all the Acyclic Orientations of an Undirected Graph, Information Processing Letters 72 (1999), $71-74$.

34. Claudson F. Bornstein and Jayme L. Szwarcfiter, A Characterization of Clique Graphs of Rooted Path Graphs, Combinatorics, Graph Theory and Algorithms, in Y. Alavi, D. R. Lick, and A. Schwenck, eds., Proceedings of the 8th Quadriennial International Conference on Graph Theory, Combinatorics, Algorithms and Applications, Western Michigan University, 1996, New Issues Press, Kalamazoo, USA, 1999, pp. 117-122.

35. Fábio Protti and Jayme L. Szwarcfiter, Clique-Inverse Graphs of $K_{3}$-free and $K_{4}$-free Graphs, Journal of Graph Theory 35 (2000), 257-272.

36. Fábio Protti and Jayme L. Szwarcfiter, On Clique Graphs with Linear Size, Congressus Numerantium 143 (2000), 207-219.

37. Márcia R. Cerioli and Jayme L. Szwarcfiter, A Characterization of Edge Clique Graphs, Ars Combinatoria 60 (2001), 287-292.

38. Edson N. Cáceres, Siang W. Song, and Jayme L. Szwarcfiter, A Coursegrained Parallel Algorithm for Maximal Cliques in Circle Graphs, Proceedings of the 2001 International Conference on Computational Sciences (ICCS' 2001), USA, 2001, Lecture Notes in Computer Science 2074 (2001), pp. 638647.

39. Fábio Protti and Jayme L. Szwarcfiter, Clique-Inverse Graphs of Bipartite Graphs, Journal of Combinatorial Mathematics and Combinatorial Computing 40 (2002).

40. Márcia R. Cerioli and Jayme L. Szwarcfiter, Edge Clique Graphs of Some Classes of Chordal Graphs, Discrete Mathematics 242 (2002), 31-39.

41. Jayme L. Szwarcfiter, "A Survey on Clique Graphs", in C. L. Sales and B. Reed, eds., Algorithms and Combinatorics, Springer-Verlag, New York, 2002.

42. Guillermo Durán, Min-Chih Lin, and Jayme L. Szwarcfiter, On Clique-Transversals and Clique-Independent Sets, to appear in Annals of Operations Research.

43. Celina M. H. de Figueiredo, John Gimbel, Célia P. de Mello and Jayme L. Szwarcfiter, A Note on Transitive Orientations with Maximum Sets of Sources and Sinks, to appear in Discrete Applied Mathematics.

44. Jayme L. Szwarcfiter, Gonzalo Navarro, Ricardo Baeza-Yates, Joísa S. Oliveira, Walter Cunto, and Nívio Ziviani, Optimal Binary Search Trees with Costs Depending on the Access Paths, to appear in Theoretical Computer Science. 